\title{
miR-200a-3p facilitates bladder cancer cell proliferation by targeting the $A 20$ gene
}

\author{
Pei Wan ${ }^{1 \#}$, Zhilin Chen ${ }^{1 \#}$, Minzhi Huang ${ }^{1 \#}$, Huiming Jiang ${ }^{1}$, Huajun Wu ${ }^{2}$, Kaihua Zhong ${ }^{1}$, Guodong Ding ${ }^{1}$, \\ Bing Wang ${ }^{1}$
}

${ }^{1}$ Department of Urology, Meizhou People's Hospital (Huangtang Hospital), Meizhou, China; ${ }^{2}$ Department of Urology, Shangrao Municipal Hospital, Shangrao, China

Contributions: (I) Conception and design: P Wan; (II) Administrative support: None; (III) Provision of study materials or patients: M Huang, H Wu, K Zhong, G Ding; (IV) Collection and assembly of data: P Wan, Z Chen, M Huang; (V) Data analysis and interpretation: Z Chen, H Jiang; (VI) Manuscript writing: All authors; (VII) Final approval of manuscript: All authors.

\#These authors contributed equally to this work.

Correspondence to: Pei Wan. Department of Urology, Meizhou People’s Hospital (Huangtang Hospital), No. 63, Huang Tang Road, Meizhou 514031, China. Email: wanpeimeizhou@163.com.

Background: MicroRNAs (miRs) are endogenous, single-stranded, noncoding RNAs that are involved in various physiological processes, and the development and the progression of various types of cancer. Specifically, the role of miR-200a-3p has been implicated in various types of cancer in contributing to a diverse array of cancer types has been previously reported. The present study aimed to investigate the expression levels of miR-200a-3p in human bladder cancer, as well as its potential role in disease pathogenesis.

Methods: Reverse transcription-polymerase chain reaction (RT-PCR) and Western blot were used to detect the expression of has-mir-200a-3p and tumor necrosis factor $\alpha(T N F-\alpha)$ induced protein $3(A 20)$ in tumor tissues and cell lines. Dual-luciferase reporter assay and combination with the expression intervention of hsa-mir-200a-3p and $A 20$ in bladder cancer cell lines to clarify the binding relationship between hsamir-200a-3p and A20.After the expression intervention of hsa-mir-200a-3p and $A 20$ in bladder cancer cells, the changes of cell proliferation, cell apoptosis, cell cycle, wound-healing ability and migration ability were detected by CCK8, flow cytometry, wound-healing and Transwell methods. Xenograft transplantation model was performed subcutaneously in nude mice by implantation of J82 and T24 cells, and then the bladder cancer growth curve was calculated from mice exposed to has-mir-200a-3p minic or minic-NC.

Results: Bladder cancer tissues demonstrated significantly upregulated miR-200a-3p expression levels. Moreover, increased miR-200a-3p expression was significantly associated with distant metastasis and advanced stage. In addition, compared with the miR-control (Ctr) group, miR-200a-3p overexpression promoted bladder cancer cell proliferation, migration, invasion, cell cycle, and release of inflammatory cytokines, but inhibited cell apoptosis. Mechanistically, A20 was identified as a target gene of miR-200a-3p in bladder cancer cell lines. Moreover, compared with the miR-Ctr group, the miR-200a-3p overexpression group exhibited significantly promoted tumor growth in vivo, and $A 20$ overexpression blocked the promoting effect of miR-200a-3p on bladder cancer.

Conclusions: The results of the present study indicated that miR-200a-3p might serve act as an oncogene in human bladder cancer by targeting a novel the gene $A 20$ gene; therefore, miR-200a-3p and $A 20$ might serve could serve as novel therapeutic targets for bladder cancer.

Keywords: MicroRNA-200a-3p (miR-200a-3p); bladder cancer; proliferation; metastasis; tumor necrosis factor $\alpha$ induced protein 3 (A20)

Submitted Oct 07, 2021. Accepted for publication Nov 12, 2021.

doi: 10.21037/tau-21-941

View this article at: https://dx.doi.org/10.21037/tau-21-941 


\section{Introduction}

Bladder cancer is one of the most common malignant tumors of the urinary system (1). Bladder cancer has a higher morbidity rate in males, with a 3 to 10 times higher incidence in males compared with females (2). Several risk factors are associated with bladder cancer, including industrial chemical contamination, poor dietary habits, and smoking (3). Surgery remains the primary treatment strategy for bladder cancer; however, an increase in its morbidity rate has been identified (4). In addition, bladder cancer exhibits a high recurrence rate with high levels of invasion and metastasis, which directly lead to poor patient prognosis (5). Therefore, novel treatments and clarification of the potential molecular mechanisms underlying bladder cancer are needed.

MicroRNAs (miRNAs/miRs) are noncoding, short, single-stranded RNAs (6). Target protein expression is commonly regulated by miRNAs via binding to the 3 'untranslated region (UTR) of substrates $(7,8)$. Specific pathological features result in altered microRNA expression, which indicates oncogenic or antioncogenic properties. Number of studies have revealed that miRNAs can regulate various gene expression levels, which in turn regulate the cellular signaling pathways associated with controlling tumor proliferation, invasion, inflammatory responses, and apoptosis (9-11).

Previous studies have indicated that miR-200a-3p is upregulated in various types of cancer, including non-small cell lung, pancreatic cancer, breast cancer, and hepatitis B virus-related hepatocellular carcinoma (12-14). In another study, it was found that when miR-200a-3p targeted the regulator of $P C D H 9$, this could suppress gastric carcinoma cell proliferation and invasion (12). In addition, other studies have shown that miR-200a-3p can directly target KLF12 and $p 21$ to inhibit the growth of gastric cancer and lung cancer (15). However, the functional roles and specific molecular mechanisms underlying miR-200a-3p in bladder cancer cells are not completely understood. Tumor necrosis factor alpha (TNF- $\alpha$ )-induced protein 3 (A20) is an important regulator of inflammation and immunity $(11,16)$. A20 has been reported to negatively regulate inflammatory responses via deubiquitination enzymatic activity and ubiquitin binding activity (17), and has also been reported to serve as an oncogene (18). Additionally, increased A20 expression is associated with a poor survival rate in patients with breast cancer (19). The association between miRNAs and A20 has been reported in numerous types of human cancer via the alteration the nuclear factor kappa- B (NF- $\mathrm{B})$ signaling pathway. For example, miR-19b-3p was shown to function as a tumor suppressor and capable of inhibiting nasopharyngeal carcinoma growth by regulating A20 (20). A20 is a potential target gene of miR-19b-3p; however, the relationship between miR-200a-3p and A20 in bladder cancer has not been previously reported (21-23). Therefore, the present study aimed to investigate the relationship between miR-200a-3p and A20 in bladder cancer and to explore the potential molecular mechanisms underlying miR-200a-3p in bladder cancer. Our results are the first of their kind in demonstrating that miR-200a-3p has significantly increased expression in bladder cancer tissues and cell lines compared with adjacent nontumor tissues and normal bladder cell lines, respectively, and facilitates bladder cancer cell proliferation, migration, and inflammatory cytokine production, but suppresses cell apoptosis via downregulating A20. The results of our study point to the important role of miR-200a-3p in regulating A20 expression, providing a potential novel therapeutic target for bladder cancer. We present the following article in accordance with the MDAR reporting checklist (available at https://dx.doi.org/10.21037/tau-21-941).

\section{Methods}

\section{Patient samples}

In the present study, 40 bladder cancer tissues and 40 adjacent nontumor tissues were collected from Meizhou People's Hospital. Patients had not received radiation therapy or chemotherapy prior to surgical treatment. The clinical stage of patients with bladder cancer was determined using the World Health Organization criteria. Tumor tissues were stored in liquid nitrogen or at $-80^{\circ} \mathrm{C}$. All procedures performed in this study involving human participants were in accordance with the Declaration of Helsinki (as revised in 2013). The study was approved by The Institutional Review Board of Meizhou People's Hospital (No. 2020-F-15) and informed consent was taken from all the patients.

\section{Cell culture and transfection}

A normal bladder cell line (SV-HUC-1) and bladder cancer cell lines (5637, J82, ECV-304, BIU-87, T24, HCV29, and H/RB-CL2) were purchased from the American Type Culture Collection (Manassas, VA, USA). 
Cells were cultured in RPMI-1640 (Invitrogen; Thermo Fisher Scientific, Waltham, MA, USA) supplemented with $10 \%$ fetal bovine serum (FBS), $2 \mathrm{mM}$ of glutamine and $100 \mu \mathrm{g} / \mathrm{mL}$ of streptomycin/penicillin (Sangon Biotech Co., Ltd., Shanghai, China) at $37^{\circ} \mathrm{C}$ with $5 \% \mathrm{CO}_{2}$.

\section{Western blotting}

Western blotting was performed as previously described. Briefly, total protein was extracted using NP40 buffer (Beijing Solarbio Science \& Technology Co., Ltd., Beijing, China) at $4{ }^{\circ} \mathrm{C}$ for 20 minutes, which was followed by centrifugation at $12,000 \times \mathrm{g}$ at $4{ }^{\circ} \mathrm{C}$ for 10 minutes. Proteins were separated via $12 \%$ SDS-PAGE and transferred to polyvinylidene fluoride (PVDF) membranes (Beijing Solarbio Science \& Technology Co., Ltd.). Following blocking with $5 \%$ bovine serum albumin (BSA) in phosphate-buffered saline with Tween 20 (PBST; 0.1\% Tween20) at room temperature for 1 hour, the membranes were incubated with primary antibodies [A20 (from cell signaling technology Co., Ltd, USA, lot \#5630), GAPDH (from cell signaling technology Co., Ltd, USA, LOT \#5174)], at $4{ }^{\circ} \mathrm{C}$ overnight. Subsequently, the membranes were incubated with a horseradish peroxidase (HRP)conjugated secondary antibody (from cell signaling technology Co., Ltd, USA, lot \# 7076) at $37{ }^{\circ} \mathrm{C}$ for 1 hour. Protein bands were visualized using enhanced chemiluminescence (ECL) reagent. GAPDH was used as the loading control.

\section{Reverse transcription-quantitative polymerase chain reaction}

Total RNA was extracted using TRIzol reagent (Invitrogen; Thermo Fisher Scientific) according to the manufacturer's protocol. Total RNA (1 mg) was reverse transcribed into complement DNA (cDNA) using the miRNA First Strand cDNA Synthesis (Tailing Reaction) reagent kit with genomic DNA (gDNA) Eraser (Sangon Biotechnology Co., Ltd., shanghai, China). Subsequently, quantitative polymerase chain reaction (qPCR) was performed using a reverse transcription qPCR (qRT-PCR) machine (Applied Biosystems; Thermo Fisher Scientific, Inc.). miRNA and messenger RNA (mRNA) expression levels were normalized to the internal reference genes U6 and GAPDH, respectively. The primer sequence used are as follows: U6F: CTCGCTTCGGCAGCACA; has-mir-200a-3p-F:
TAACACTGTCTGGTAACGATG.

\section{Apoptosis analysis and cell cycle analysis}

Different groups of cells were collected, with no less than $1 \times 10^{5}$ cells in each group. Cells were washed with PBS twice. According to the instructions of the apoptotic kit (KeyGEN Biotech, Nanjing, China), dyes were added in turn and protected from light for 10 minutes, with a flow cytometer (ACEA Biosciences, San Diego, CA, USA) being used for detection and analysis. Different groups of cells were collected, washed with PBS twice, and then fixed by $70 \%$ ethanol overnight. According to instructions of the cell cycle kit manufacturer (KeyGEN Biotech), dyes were added sequentially, protected from light for 30 minutes, and analyzed by flow cytometry (ACEA Biosciences, USA).

\section{Cell counting Kit-8 assay}

Cells $\left(1 \times 10^{4}\right.$ cells/well) were seeded into 96-well plates. Following culture for 48 or 72 hours, cell proliferation was analyzed by performing the Cell Counting Kit-8 (CCK-8) assay (Dojindo Molecular Technologies, Inc., Rockville, MD, USA) according to the manufacturer's protocols. Absorbance was measured at a wavelength of $450 \mathrm{~nm}$ using a Multiskan GO Microplate Spectrophotometer (Thermo Fisher Scientific).

\section{Cell migration assay}

Cell migration was measured using $6.5-\mathrm{mm}$ Transwell inserts with $8.0-\mathrm{mm}$ pore polycarbonate membranes (Costar; Corning Inc., Corning, NY, USA). Cell invasion was assessed using $6.5-\mathrm{mm}$ Transwell inserts with $8.0-\mathrm{mm}$ pore polycarbonate membranes (Costar; Corning Inc.). Cell migration and invasion were determined as previously described. Subsequently, the average number of migratory or invading cells was counted.

\section{Wound bealing assay}

At 24 or 36 hours post transfection, cells were harvested and cultured for a further 24 hours. Subsequently, a single scratch in the cell monolayer was made using a $300-\mu \mathrm{L}$ sterile pipette. The wounds were observed at 24 hours. The intersection of the bottom line and the cell scratch line was considered as the observation point. The plate for wound- 
healing experiment was photographed, and the width of the scratch in each hole was converted according to the corresponding scale of the picture, to obtain the change of the width of the scratch in each time period. Statistics were made according to the width of different times, and the change of the wound-healing speed in each group was analyzed.

\section{Dual-luciferase reporter assay}

The wild-type (WT) A20 3'UTR sequence was amplified via PCR and cloned into the pmirGLO vector (Promega Corporation, Madison, WI, USA). To construct the mutant (Mut) plasmid, the complementary sequences for miR-200a-3p in the 3'UTR of A20 were mutated. J82 and T24 cells were co-transfected with A20-WT or A20Mut and miR-200a-3p mimic or miR-NC. At 36 hours post transfection, luciferase activities were measured using the Dual-Luciferase Reporter Assay System (Promega Corporation).

\section{Tumor growth in vivo}

The function of miR-200a-3p in bladder cancer growth was assessed by evaluating tumor growth in vivo. Male nude mice (age, 6 weeks; $n=6$ per group) were used to assess tumor growth and metastasis. To assess tumor growth, mice were subcutaneously injected with miR-200a-3poverexpression or control cells $\left(1 \times 10^{5}\right)$. Tumor volume was calculated at 1, 2, 3 and 4 weeks postinjection. At 4 weeks postinjection, all mice were euthanized, and the tumors were isolated. The animal experiments were compliance with Meizhou People's Hospital guidelines for the care and use of animals. All animal experiments were approved by the ethics committee of Meizhou People's Hospital. Male nude mice (age, 6 weeks) were bought from Guangdong Experimental Animal Center (Number: SYXK.2020-0237).

\section{Statistical analysis}

Data are presented as the mean \pm SD from at least 3 independent repeats. Statistical analyses were performed using SPSS software (version 19.0; IBM Corp., Armonk, NY, USA). Comparisons among multiple groups were analyzed using 1-way or 2-way analysis of variance (ANOVA)_ followed by Bonferroni's post hoc test. Comparisons between 2 groups were analyzed using a paired or unpaired $t$-test. A P value $<0.05$ was considered to indicate a statistically significant difference.

\section{Results}

miR-200a-3p expression levels were significantly increased in bladder cancer tissues

To investigate the role of miR-200a-3p in bladder cancer, three bladder cancer tissues and adjacent non-tumor tissues were sent to Guangzhou Sage Bioscience for Agilent miRNA microarray analysis. Sequencing results showed that the expression of miR-200a-3p in cancer tissues was higher than that in non-tumor tissues, and the comprehensive score of differential expression of miR-200a-3p was among the top ten in the results of microarray (Figure S1A). Further, we used Cbioportal database to find the expression of miR-200a-3p in bladder cancer, that the expression of miR-200a-3p in bladder cancer tissues was higher than that in normal tissues (Figure S1B). To further clarify the expression of miR-200a-3p in bladder cancer, miR-200a$3 p$ expression levels in bladder tumor tissues $(n=40)$ and adjacent nontumor tissues $(\mathrm{n}=40)$ were determined via $\mathrm{qRT}$ PCR. miR-200a-3p expression was significantly upregulated in bladder cancer tissues compared with adjacent nontumor tissues (Figure 1A). Moreover, miR-200a-3p expression levels were also significantly upregulated in advanced clinical stage bladder cancer tissues $(n=20$ per stage) compared with earlier clinical stage bladder cancer tissues (Figure 1B), with the highest expression levels observed in stage III and IV metastatic bladder cancer tissues. Moreover, miR-200a-3p expression was also significantly increased in the various bladder cancer cell lines compared with the normal bladder cell line (Figure 1C). Collectively, the results suggested that miR-200a-3p was upregulated in bladder cancer tissues compared with adjacent nontumor tissues, indicating that miR-200a-3p may serve a stimulative role in bladder cancer development.

\section{miR-200a-3p overexpression facilitated cell proliferation via suppressing apoptosis, but promoted inflammatory cytokine production}

To assess the role of miR-200a-3p in bladder cancer development, miR-200a-3p was successfully overexpressed in $\mathrm{J} 82$ and T24 cell lines (Figure 2A). To further explore the role of miR-200a-3p in bladder cancer, cell proliferation assays were performed. Cell proliferation was significantly increased at 48- and 72-hours following transfection with 

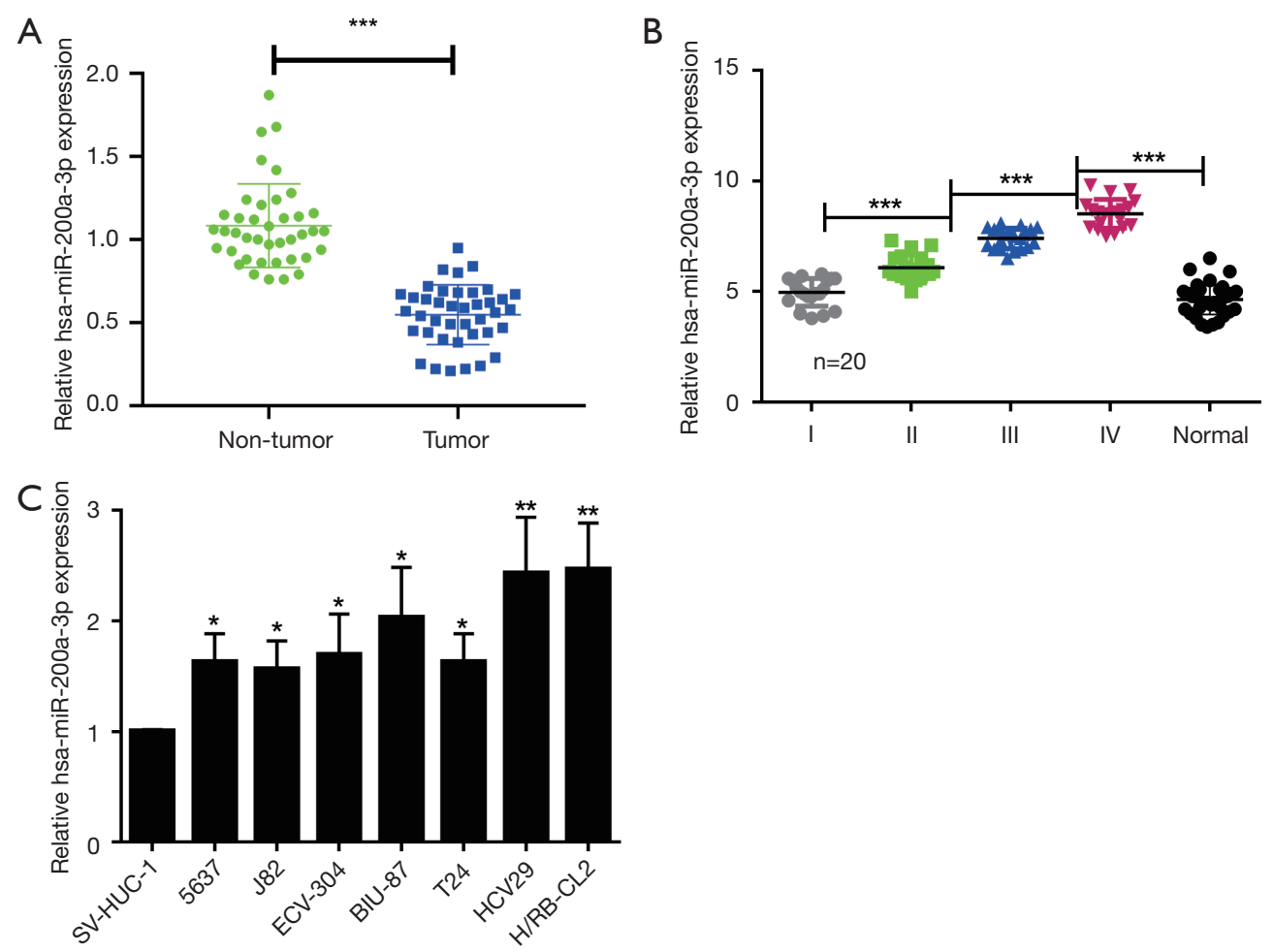

Figure 1 miR-200a-3p was upregulated in bladder cancer tissues. (A) miR-200a-3p expression levels in GC tissues and adjacent nontumor tissues. ${ }^{* *}, \mathrm{P}<0.001$ by a paired $t$-test. (B) miR-200a-3p expression levels in patients with 4 different clinical stages of bladder cancer. ***, $\mathrm{P}<0.001$ by 1 -way ANOVA followed by Bonferroni's post hoc test. (C) miR-200a-3p expression levels in bladder cancer cell lines and a normal human bladder cell line. *, $\mathrm{P}<0.05$ and **, $\mathrm{P}<0.01$ vs. SV-HUC-1 by 1 -way ANOVA followed by Bonferroni's post hoc test. Data are presented as the mean $\pm \mathrm{SD}$ of 3 independent experiments. miR, microRNA.
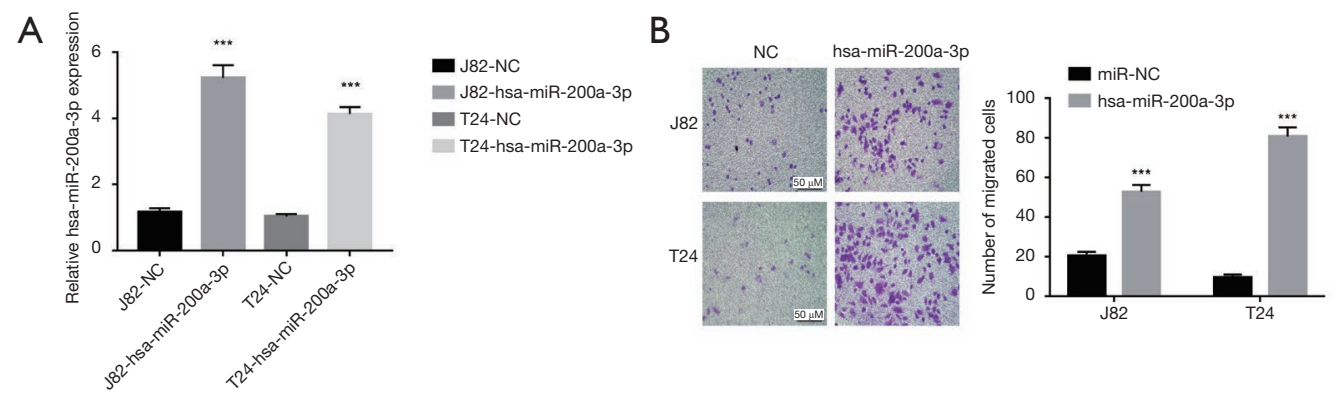

C
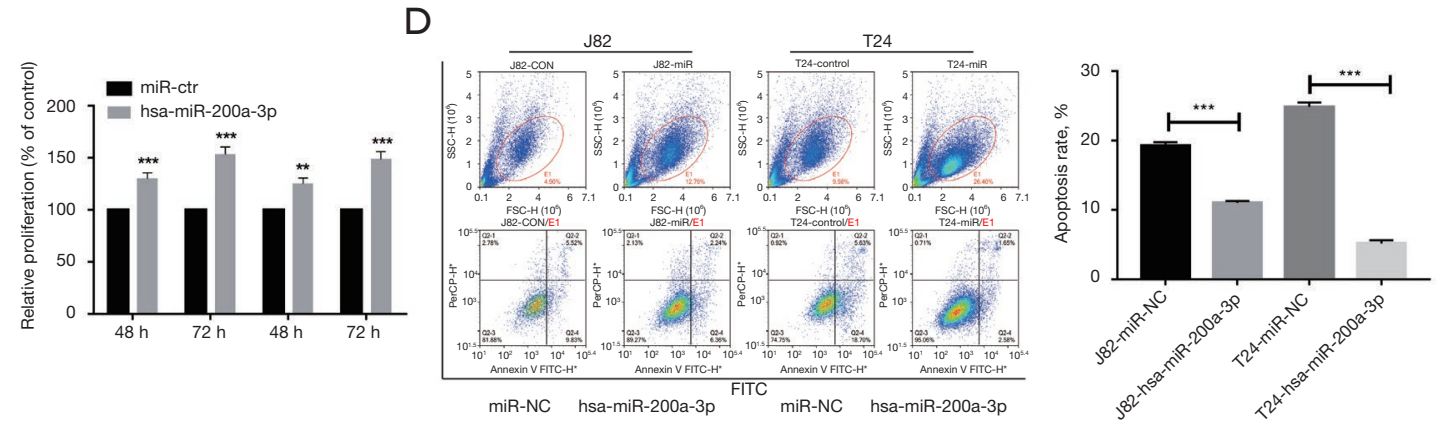

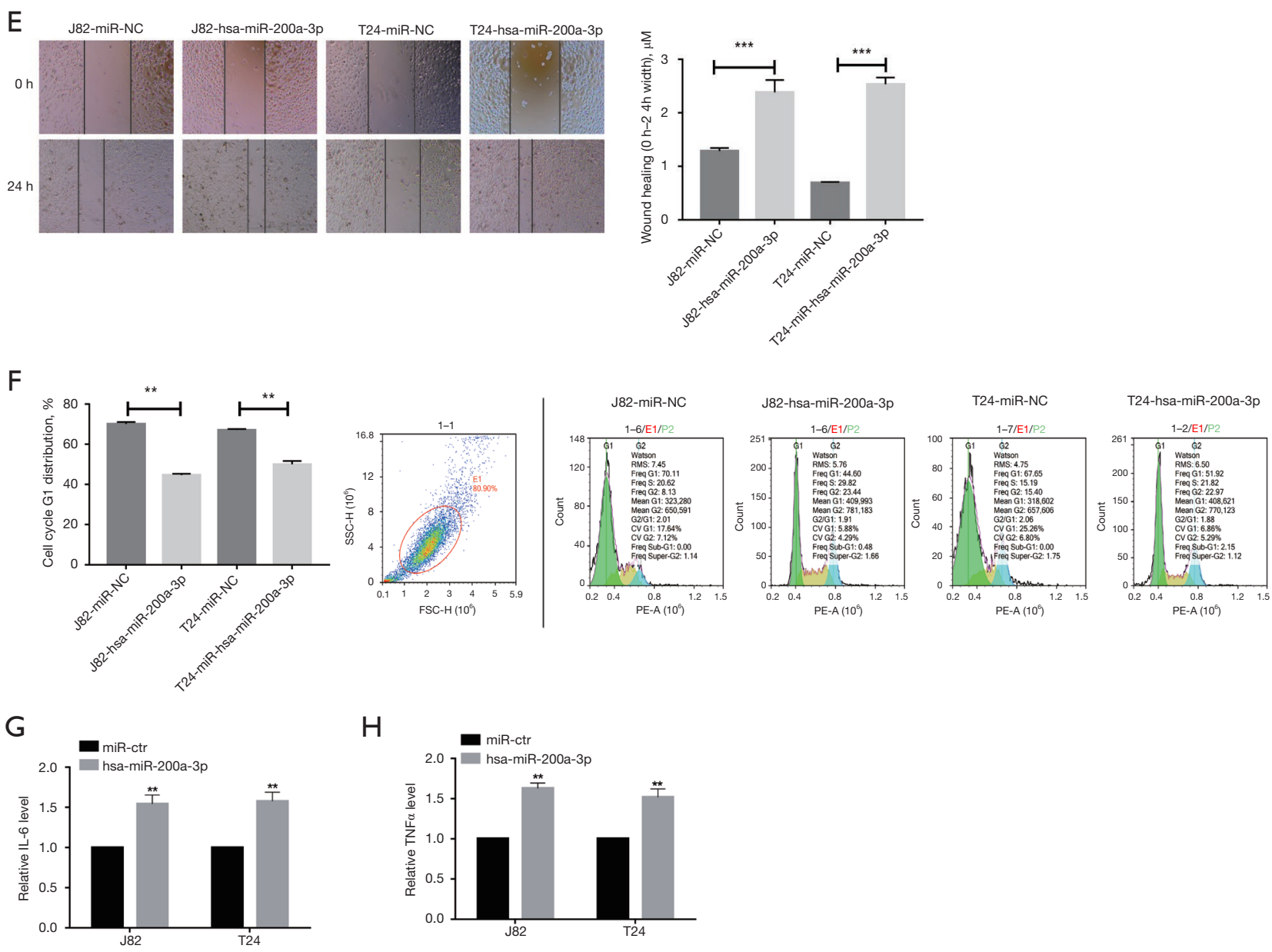

Figure $2 \mathrm{miR}-200 \mathrm{a}-3 \mathrm{p}$ overexpression facilitated cell proliferation via suppressing apoptosis and inflammatory cytokine production. (A) Transfection efficacy of miR-200a-3p mimic in J82 and T24 cells. ${ }^{* * *}, \mathrm{P}<0.001 v s$. miR-NC by an unpaired $t$-test. (B) Effect of miR-200a-3p overexpression on $\mathrm{J} 82$ and T24 cell proliferation as determined by performing Cell Counting Kit- 8 assays. ***, $\mathrm{P}<0.001$ vs. miR-NC by 2 -way ANOVA followed by Bonferroni's post hoc test. (C) Effect of miR-200a-3p overexpression on J82 and T24 cell migration. **, P<0.01 and ***, $\mathrm{P}<0.001 v s$. miR-NC by an unpaired $t$-test. (D) Effect of miR-200a-3p overexpression on J82 and T24 cell apoptosis. ***, $\mathrm{P}<0.001 v s$. miR$\mathrm{NC}$ by an unpaired $t$-test. (E) Effect of miR-200a-3p overexpression on J82 cell migration. ${ }^{* * *}, \mathrm{P}<0.001$ vs. miR-NC by an unpaired $t$-test. (F) Effect of miR-200a-3p overexpression on the cell cycle distribution in J82 cells. **, $\mathrm{P}<0.01$ vs. miR-NC by an unpaired $t$-test. Effect of miR-200a-3p overexpression on (G) IL-6 and (H) TNF- $\alpha$ levels in J82 and T24 cells. ${ }^{* *}, \mathrm{P}<0.01$ vs. miR-NC by an unpaired $t$-test. Data are presented as the mean $\pm \mathrm{SD}$ of 3 independent experiments. miR, microRNA; NC, control.

miR-200a-3p mimic in J82 and T24 cells compared with transfection with miR-Ctr (Figure 2B). Cell migration was also significantly increased in miR-200a-3p mimictransfected cells compared with miR-NC-transfected cells, which was consistent with the CCK-8 proliferation assay results (Figure 2C). In addition, miR-200a-3p overexpression significantly inhibited J82 and T24 cell apoptosis compared with the miR-NC group (Figure 2D). The wound healing assay results demonstrated that miR-200a-3p overexpression remarkably facilitated J82 and T24 cell migration compared with that of miR-NC (Figure 2E). Furthermore, miR-200a-3p overexpression greatly promoted cell cycle progression by supporting the G1 phase when compared to transfection with miR-NC (Figure $2 F$ ). Compared with the miR-NC group, the miR-200a-3poverexpressed group showed a significantly promoted release of inflammatory cytokines interleukin 6 (IL-6) and TNF- $\alpha$ in J82 and T24 cells (Figure 2G,2H). Collectively, the results demonstrated that miR-200a-3p overexpression promoted bladder cancer progression. 


\section{A20 was a target of miR-200a-3p}

The results demonstrated that miR-200a-3p possessed a complementary sequence with A20 mRNA (Figure $3 A$ ). To further verify A20 as a target of miR-200a-3p, the complementary sequence was mutated and dual-luciferase reporter assays were performed. The dual-luciferase reporter assay results indicated that miR-200a-3p overexpression significantly inhibited the luciferase activity of A20WT compared with that of miR-NC, but miR-200a-3p overexpression did not significantly alter the luciferase activity of A20-Mut compared with miR-NC (Figure 3B), which suggested that miR-200a-3p bound to the 3'UTR of A20. Compared with the miR-NC group, the miR-200a$3 \mathrm{p}$-overexpressed group showed significantly decreased A20 mRNA expression levels and notably decreased A20 protein expression levels in $\mathrm{J} 82$ and T24 cells (Figure 3C). To further elucidate the function of A20 in bladder cancer, the expression level of A20 in various bladder cancer cell lines was assessed. Compared with the normal bladder cell line, the 7 bladder cancer cell lines showed significantly decreased A20 mRNA expression and A20 protein expression levels (Figure 3D). Moreover, A20 mRNA expression levels were significantly reduced in bladder tumor tissues (Figure $3 E$ ) at different stages of tumor growth (Figure $3 F$ ) compared with adjacent nontumor tissues and the control group, respectively. A20 protein expression levels displayed a similar trend. Therefore, in contrast to the expression levels of miR-200a-3p in bladder cancer, A20 expression was significantly decreased in bladder cancer tissues compared with adjacent nontumor tissues (Figure 1B). The aforementioned results demonstrated that A20 was a target of miR-200a-3p, indicating that miR-200a-3p downregulated A20 expression by binding to its 3'UTR.

\section{A20 reversed the effects of miR-200a-3p overexpression on bladder cancer cells}

Compared with adjacent nontumor tissues, bladder cancer tissues showed upregulation expression of miR-200a-3p but downregulated expression of A20, with miR-200a-3p downregulating A20. Therefore, we investigated whether miR-200a-3p regulated bladder cancer development via targeting A20. A20 overexpression restored A20 expression levels in miR-200a-3p-overexpressed J82 and T24 cells (Figure $4 A$ ), which resulted in the inhibition of miR-200a$3 \mathrm{p}$ overexpression-mediated effects on cell proliferation (Figure 4B), migration (Figure 4C), and apoptosis
(Figure 4D). The expression of A20 protein was increased after transfection of J82 and T24 cells with A20 overexpression plasmid (Figure S2).

\section{Effects of A20 on bladder cancer cells in vivo}

A20 overexpression significantly promoted IL-6 (Figure 5A) and TNF- $\alpha$ (Figure $5 B$ ) production in miR-200a-3poverexpressed J82 and T24 cells. The results suggested that miR-200a-3p promoted bladder cancer progression via $\mathrm{A} 20$ in vitro. To further investigate the role of $\mathrm{miR}$ $200 \mathrm{a}-3 \mathrm{p}$ in promoting bladder cancer progression, miR200a-3p mimic-transfected or miR-200a-3p mimic + A20 overexpression-transfected T24 cells were injected into nude mice, and the rate of tumor growth was assessed (Figure 5C). A2 0 overexpression reversed miR-200a-3p-mediated promotion of tumor growth as indicated by alterations in tumor volume (Figure 5C) and A20 expression in vivo (Figure 5D). The results thus demonstrated that miR$200 a-3 p$ promoted bladder cancer progression in vivo. Collectively, the aforementioned results demonstrated that miR-200a-3p facilitated bladder cancer progression via A20.

\section{Discussion}

Bladder cancer has become one of the most common malignant tumors of the urinary tract; therefore, identifying those oncogenes associated with bladder cancer is essential for the development of effective therapeutic strategies (24). Although advances in diagnosis and treatment have improved the long-term survival of patients with early bladder cancer, the prognosis of advanced stage bladder cancer remains poor (22). Early bladder cancer has few symptoms, which makes it difficult to diagnose, and thus bladder cancer is typically diagnosed during the advanced stages (16). An increasing number of studies have identified certain molecular mechanisms underlying bladder cancer progression. It is widely acknowledged that tumor cells often rely on oncoproteins to continue to proliferate and survive and that cyclin-dependent kinases (CDKs) directly and critically affect the cell-cycle transitions of all eukaryotic organisms. Both Chen et al. and Tang et al. demonstrated that miR-200a-3p suppresses cell invasion and migration by directly targeting ZEB1 and p21 in bladder cancer and lung cancer $(15,25,26)$. However, there is insufficient understanding concerning the development of effective therapeutic strategies for bladder cancer. Increasing evidence has indicated that miRNAs contribute to bladder 
A

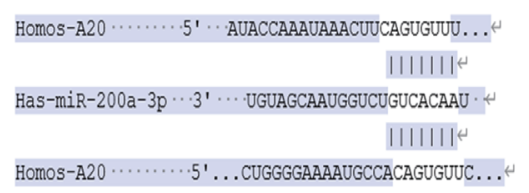

C

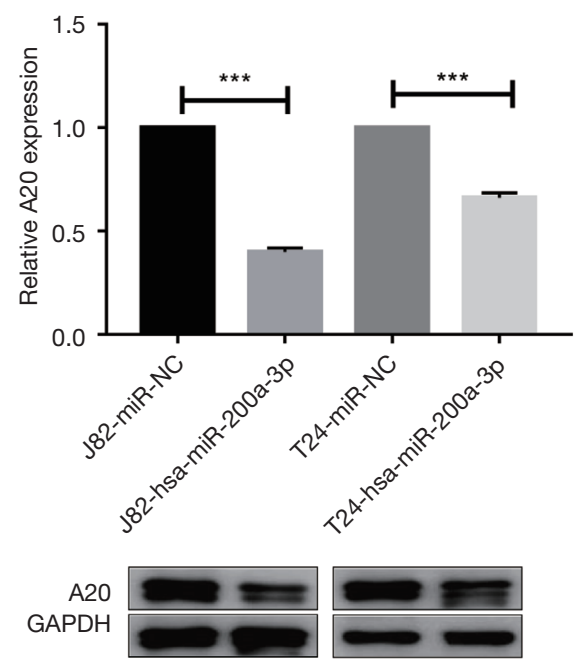

$\mathrm{E}$

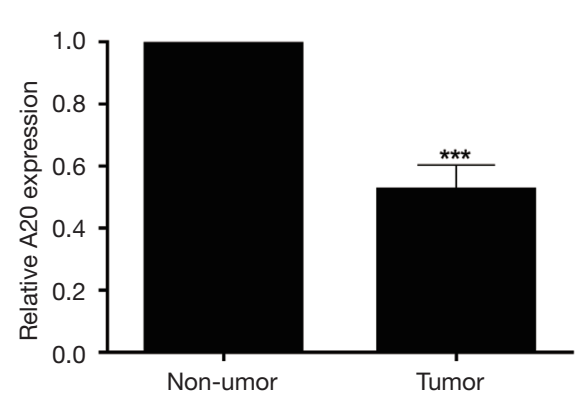

A20

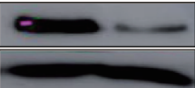

B

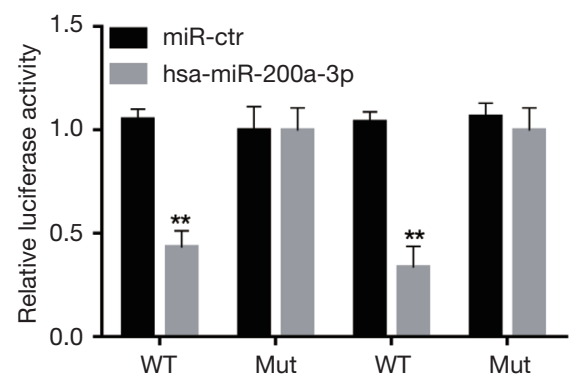

$\mathrm{D}$

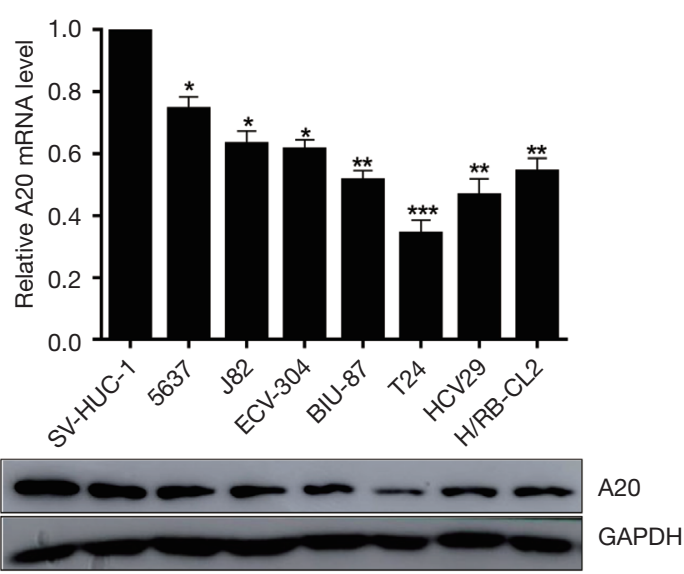

$\mathrm{F}$
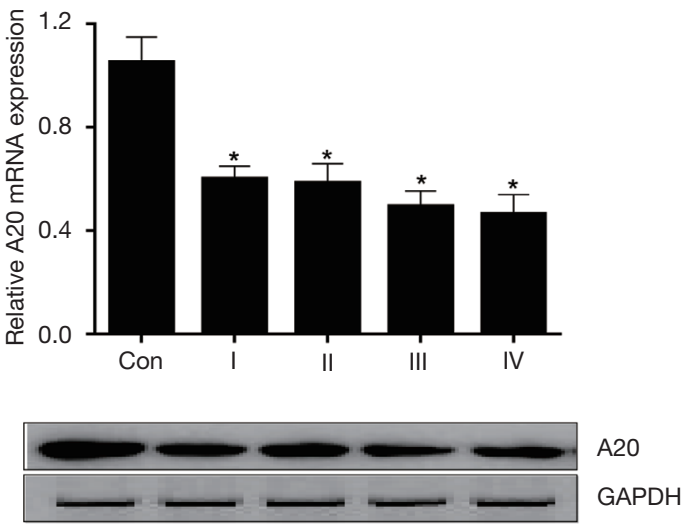

Figure 3 A20 was a target of miR-200a-3p. (A) Binding sites between the 3'UTR of A20 and miR-200a-3p. (B) Effect of miR-200a-3p overexpression on the luciferase activity of A20-WT and A20-Mut in J82 and T24 cells. ${ }^{* *}, \mathrm{P}<0.01$ ss. miR-NC by 2 -way ANOVA followed by Bonferroni's post hoc test. (C) Effect of miR-200a-3p overexpression on A20 mRNA and protein expression levels in J82 and T24 cells. ${ }^{* * *}, \mathrm{P}<0.001 v s$. miR-NC by an unpaired $t$-test. (D) A20 mRNA and protein expression levels in bladder cancer cell lines. ${ }^{*}, \mathrm{P}<0.05$, **, $\mathrm{P}<0.01$ and ${ }^{* * *}, \mathrm{P}<0.001$ vs. miR-NC by 1-way ANOVA followed by Bonferroni's post hoc test. (E) A20 expression levels in bladder cancer tissues and adjacent non-tumor tissues. ${ }^{* * *}, \mathrm{P}<0.001 v s$. non-tumor by a paired $t$-test. (F) A20 expression levels in different clinical stage bladder cancer tissues. *, $\mathrm{P}<0.05$ vs. NC by 1-way ANOVA followed by Bonferroni's post hoc test. Data are presented as the mean \pm SD of 3 independent experiments. A20, TNF- $\alpha$-induced protein 3; miR, microRNA; UTR, untranslated region; WT, wild-type; Mut, mutant; NC, control. 
A

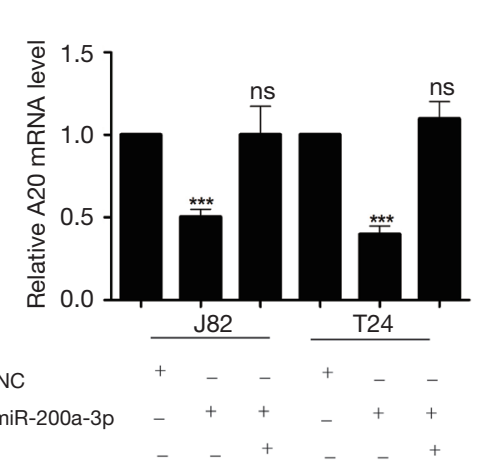

hsa-miR-200a-3p

A20
B

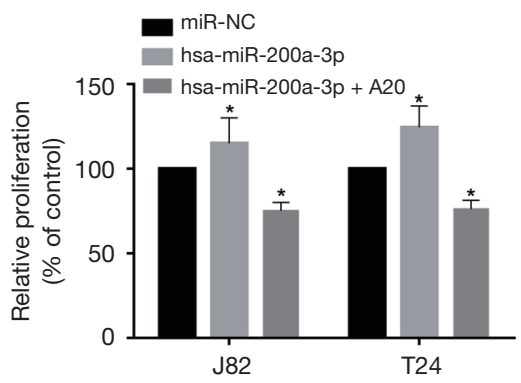

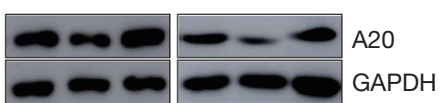

GAPDH

C

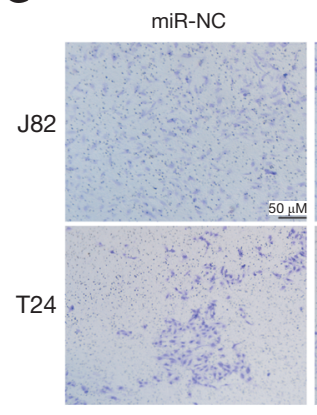

hsa-miR-200a-3p

hsa-miR-200a-3p + A20
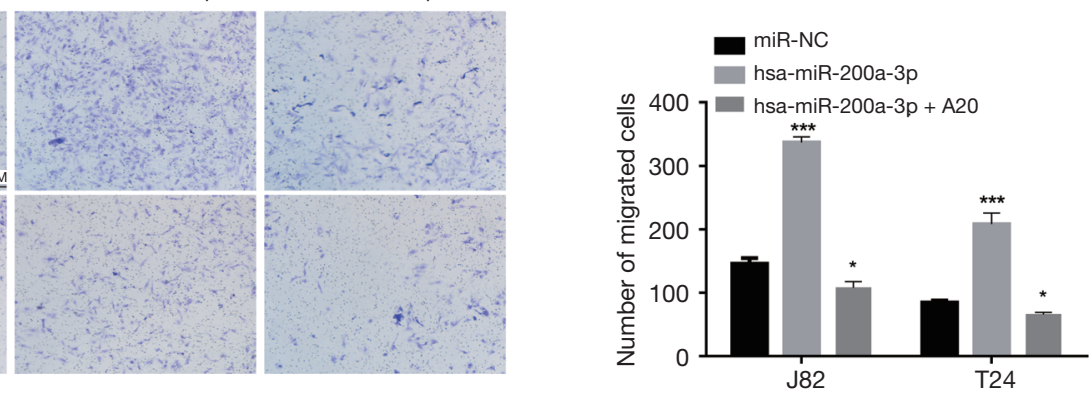

D
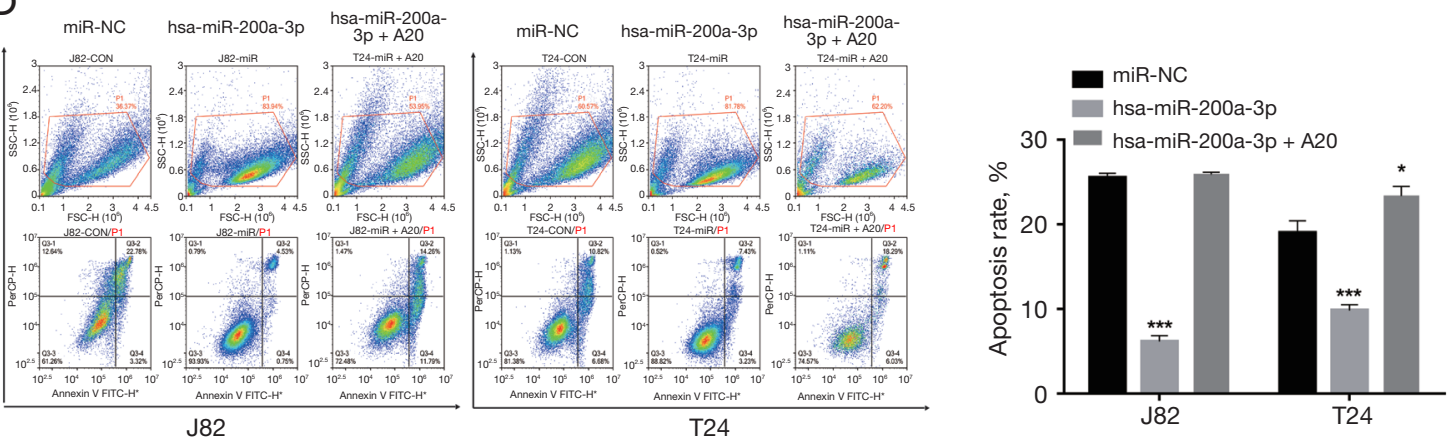

Figure 4 A20 reversed miR-200a-3p overexpression-mediated effects on bladder cancer cells. (A) Effect of A20 overexpression on A20 expression levels in miR-200a-3p-overexpressed J82 and T24 cells. ns, $\mathrm{P}>0.05 ;{ }^{* * *}, \mathrm{P}<0.001$ vs. miR-NC by 1-way ANOVA followed by Bonferroni's post hoc test. (B) Effect of A20 overexpression on cell proliferation in miR-200a-3p-overexpressed J82 and T24 cells. *, P<0.05 vs. miR-NC by 1-way ANOVA followed by Bonferroni's post hoc test. (C) Effect of A20 overexpression on cell migration in miR-200a-3poverexpression J82 and T24 cells. Cells are stained with crystal violet. ${ }^{*}, \mathrm{P}<0.05$, ${ }^{* * *}, \mathrm{P}<0.001$ vs. miR-NC by 1-way ANOVA followed by Bonferroni's post hoc test. (D) Effect of A20 overexpression on cell apoptosis in miR-200a-3p-overexpression J82 and T24 cells. *, P<0.05, ***, $\mathrm{P}<0.001$ vs. miR-NC by 1-way ANOVA followed by Bonferroni's post hoc test. Data are presented as the mean $\pm \mathrm{SD}$ of 3 independent experiments. A20, TNF- $\alpha$-induced protein 3; miR, microRNA; NC, negative control.

cancer development and progression (3). However, the role of A20 in bladder cancer progression is not completely understood. A20 has been reported to regulate type I interferon production, apoptosis, autophagy, and inflammatory responses (27). A key approach for analyzing the mechanisms underlying bladder cancer development is gene expression profile analysis. In the present study, the expression levels of miR-200a-3p and A20 in tumor tissues 
A

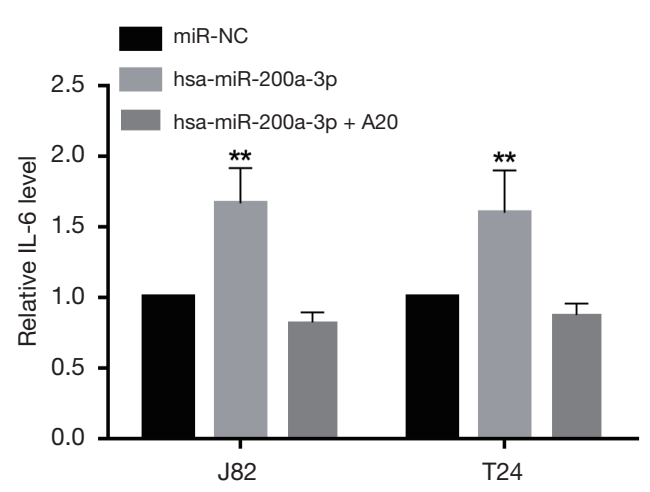

C

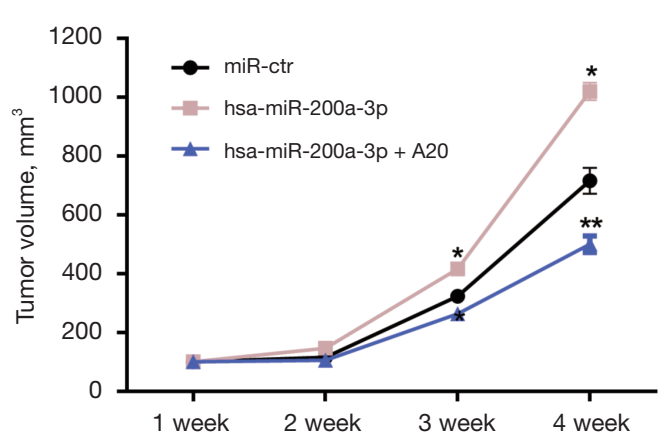

D

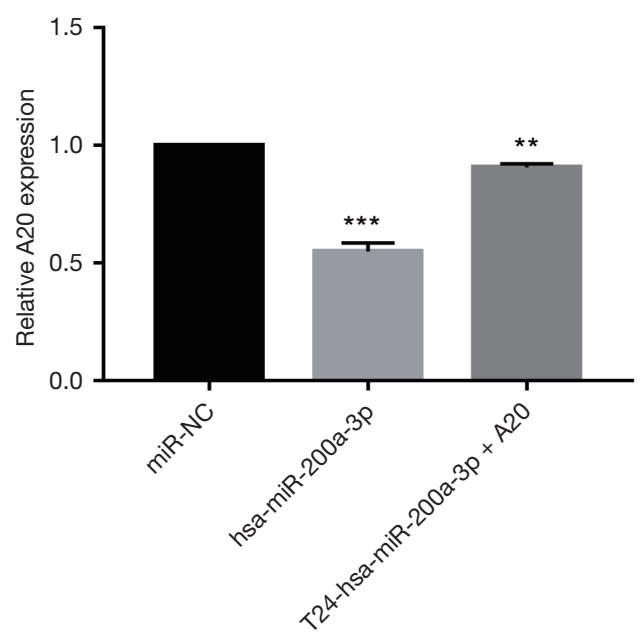

B
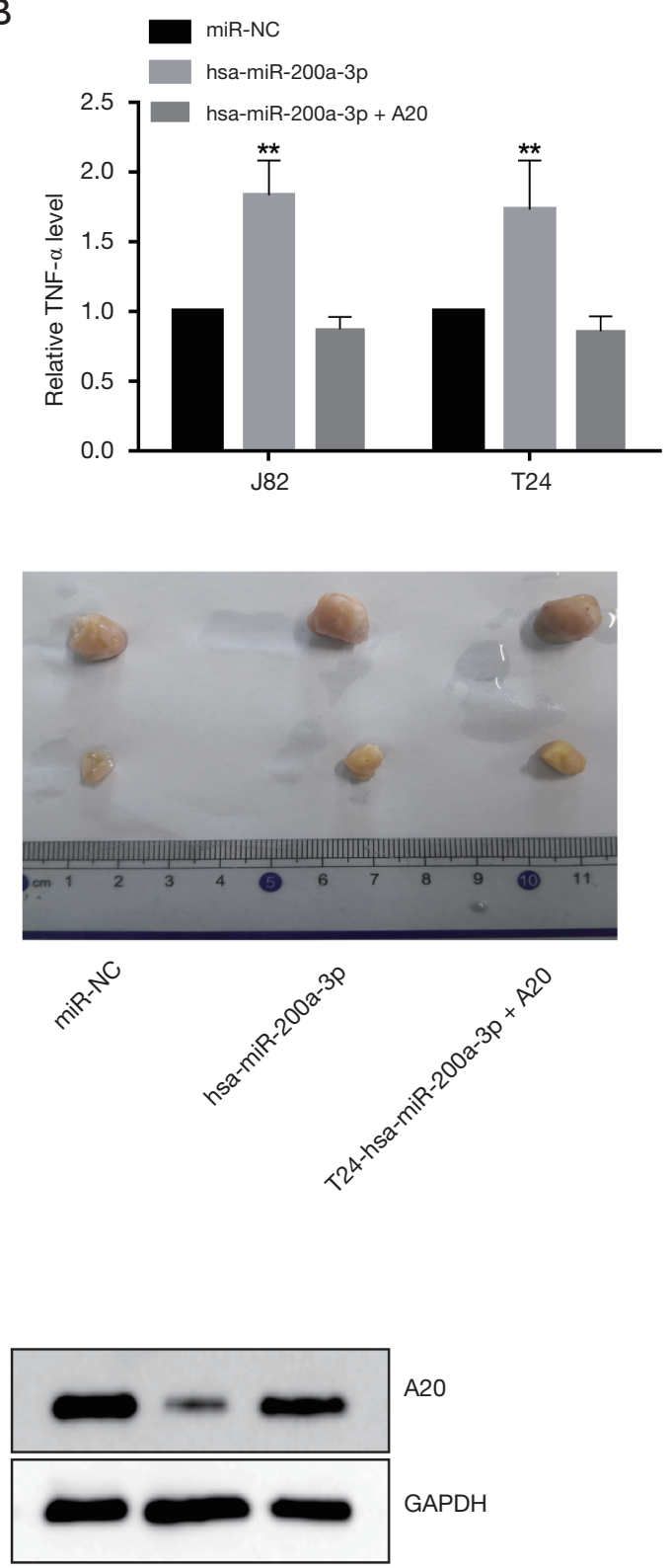

Figure 5 Effect of A20 on bladder cancer cells in vivo. Effect of A20 overexpression on the production of inflammation cytokines (A) IL-6 and (B) TNF- $\alpha$ by miR-200a-3p-overexpressed J82 and T24 cells. ${ }^{* *}, \mathrm{P}<0.01$ vs. miR-NC by 1 -way ANOVA followed by Bonferroni's post hoc test. (C) Tumor growth curves and representative images of tumors isolated from nude mice. Transfected J82 cells were subcutaneously injected into nude mice ( $\mathrm{n}=6$ per group). * $\mathrm{P}<0.05,{ }^{* *}, \mathrm{P}<0.01$ vs. miR-NC by 1 -way ANOVA followed by Bonferroni's post hoc test. (D) A20 protein expression levels were measured at the endpoint of the experiment. **, $\mathrm{P}<0.01$, ***, $\mathrm{P}<0.001$ vs. miR-Ctr by 1 -way ANOVA followed by Bonferroni's post hoc test. Data are presented as the mean \pm SD of 3 independent experiments. A20, TNF- $\alpha$-induced protein 3 ; miR, microRNA; NC, negative control; ns, not significant. 
and adjacent nontumor tissues isolated from patients with bladder cancer were assessed. The results demonstrated that miR-200a-3p was significantly upregulated while A20 was significantly downregulated in bladder cancer tissues compared with adjacent nontumor tissues. Previous studies have suggested that altered miRNA expression is closely associated with various types of cancer. Several miRNAs can function as oncogenes, while other miRNAs can function as tumor suppressor genes. In the present study, miR-200a3 p was significantly upregulated in bladder cancer tissues and cell lines compared with adjacent nontumor tissues and a normal bladder cell line, respectively. Compared with the miR-NC group, the miR-200a-3p-overexpressed group exhibited bladder cancer cell migration and proliferation, which suggests that miR-200a-3p functions as an oncogene in bladder cancer. The results of the present study were consistent with those of a previous study that reported the oncogenic role of miR-200a-3p in other types of cancer (28). Therefore, miR-200a-3p may be universal oncogene, which suggests that it might serve as a putative target for developing therapeutics for bladder cancer.

Cell proliferation and migration are signs of cancer. Advanced stages of cancer involve proliferation, resistance to apoptosis, and inflammatory cytokine production. A20 has been reported participate in hepatocellular carcinoma, pancreatic cancer, and breast cancer (8). In the present study, A20 expression was significantly decreased in bladder cancer tissues compared with adjacent nontumor tissues, and A20 overexpression attenuated miR-200a-3p overexpression-induced development and progression of bladder cancer. The results also demonstrate that miR200a-3p targets the 3'UTR of A20. Moreover, compared with the miR-NC group, miR-200a-3p overexpression increased cell proliferation and inflammatory cytokine release, but decreased cell apoptosis in bladder cancer cell lines. In the study of Ilaria Cavallari et al., the content of mir-200a-3p in urine was related to the prognosis of bladder cancer (29). The results of the present study suggest that A20 overexpression in miR-200a-3p-overexpressed cell lines can attenuate the progression of bladder cancer phenotypes, indicating a tumor suppressor function of A20 in bladder cancer, suggesting that mir-200a-3p can be used as a potential biomarker to monitor the progression of bladder cancer and the effect of drug therapy.

The results of the present study also suggest that miR200a-3p can suppress bladder cancer progression via targeting A20. With reference to the miR-NC group, it was found that miR-200a-3p overexpression could facilitate bladder cancer development, whereas A20 overexpression was found to inhibit miR-200a-3p-induced promotion of bladder cancer. The deficiency of this study is that the signaling pathway of A20 regulating cell proliferation in bladder cancer was not studied, and the related miRNA molecules lncRNA and Cir-RNA were not jointly studied. Subsequent studies will combine lncRNA and CIR-RNA to conduct further studies on A20-related signaling pathway. In summary, to the best of our knowledge, the present study is the first to provide evidence for the oncogenic role of miR-200a-3p via A20 in bladder cancer. miR-200a3 p downregulated A20 expression by binding to its 3'UTR, resulting in enhanced bladder cancer proliferation and migration via promoting cell apoptosis and inhibiting inflammatory cytokine production, providing a biomarker of the prognosis of bladder cancer and a potential novel therapeutic target for bladder cancer.

\section{Acknowledgments}

Funding: This work was supported by Meizhou People's Hospital Cultivation research Project (No. PY-C2020012).

\section{Footnote}

Reporting Checklist: The authors have completed the MDAR reporting checklist. Available at https://dx.doi. org/10.21037/tau-21-941

Data Sharing Statement: Available at https://dx.doi. org/10.21037/tau-21-941

Conflicts of Interest: All authors have completed the ICMJE uniform disclosure form (available at https://dx.doi. org/10.21037/tau-21-941). The authors have no conflicts of interest to declare.

Ethical Statement: The authors are accountable for all aspects of the work in ensuring that questions related to the accuracy or integrity of any part of the work are appropriately investigated and resolved. All procedures performed in this study involving human participants were in accordance with the Declaration of Helsinki (as revised in 2013). The study was approved by The Institutional Review Board of Meizhou People's Hospital (No. 2020-F-15) and informed consent was taken from all the patients. The animal experiments were compliance with Meizhou People's Hospital guidelines for the care and use of animals. All 
animal experiments were approved by the ethics committee of Meizhou People's Hospital.

Open Access Statement: This is an Open Access article distributed in accordance with the Creative Commons Attribution-NonCommercial-NoDerivs 4.0 International License (CC BY-NC-ND 4.0), which permits the noncommercial replication and distribution of the article with the strict proviso that no changes or edits are made and the original work is properly cited (including links to both the formal publication through the relevant DOI and the license). See: https://creativecommons.org/licenses/by-nc-nd/4.0/.

\section{References}

1. Antoni S, Ferlay J, Soerjomataram I, et al. Bladder Cancer Incidence and Mortality: A Global Overview and Recent Trends. Eur Urol 2017;71:96-108.

2. Kurozumi A, Goto Y, Okato A, et al. Aberrantly expressed microRNAs in bladder cancer and renal cell carcinoma. J Hum Genet 2017;62:49-56.

3. Black AJ, Black PC. Variant histology in bladder cancer: diagnostic and clinical implica-tions. Transl Cancer Res 2020;9:6565-75.

4. Alayev A, Salamon RS, Schwartz NS, et al. Combination of Rapamycin and Resveratrol for Treatment of Bladder Cancer. J Cell Physiol 2017;232:436-46.

5. Sathe A, Nawroth R. Targeting the PI3K/AKT/ mTOR Pathway in Bladder Cancer. Methods Mol Biol 2018;1655:335-50.

6. Liu D, Zhang C, Li X, et al. MicroRNA-567 inhibits cell proliferation, migration and invasion by targeting FGF5 in osteosarcoma. EXCLI J 2018;17:102-12.

7. Ahluwalia JK, Soni K, Sivasubbu S, et al. Modeling SNP mediated differential targeting of homologous 3'UTR by microRNA. RNA Biol 2012;9:351-60.

8. Zhang L, Yang CS, Varelas X, et al. Altered RNA editing in 3' UTR perturbs microRNA-mediated regulation of oncogenes and tumor-suppressors. Sci Rep 2016;6:23226.

9. Dalgard CL, Gonzalez M, deNiro JE, et al. Differential microRNA-34a expression and tumor suppressor function in retinoblastoma cells. Invest Ophthalmol Vis Sci 2009;50:4542-51.

10. Du WW, Fang L, Li M, et al. MicroRNA miR-24 enhances tumor invasion and metastasis by targeting PTPN9 and PTPRF to promote EGF signaling. J Cell Sci 2013;126:1440-53.

11. Nishikawa R, Goto Y, Sakamoto S, et al. Tumor- suppressive microRNA-218 inhibits cancer cell migration and invasion via targeting of LASP1 in prostate cancer. Cancer Sci 2014;105:802-11.

12. Shi C, Yang Y, Zhang L, et al. MiR-200a-3p promoted the malignant behaviors of ovarian cancer cells through regulating PCDH9. Onco Targets Ther 2019;12:8329-38.

13. Wei S, Wang K, Huang X, et al. LncRNA MALAT1 contributes to non-small cell lung cancer progression via modulating miR-200a-3p/programmed deathligand 1 axis. Int J Immunopathol Pharmacol 2019;33:2058738419859699.

14. Zhang C, Wang GX, Fu B, et al. LncRNA CASC15 promotes migration and invasion in prostate cancer via targeting miR-200a-3p. Eur Rev Med Pharmacol Sci 2020;24:7215.

15. Tang Y, Cui Y, Li Z, et al. Radiation-induced miR-208a increases the proliferation and radioresistance by targeting p21 in human lung cancer cells. J Exp Clin Cancer Res 2016;35:7.

16. Pan Q, Sathe A, Black PC, et al. CDK4/6 Inhibitors in Cancer Therapy: A Novel Treatement Strategy for Bladder Cancer. Bladder Cancer 2017;3:79-88.

17. Vande Walle L, Van Opdenbosch N, Jacques P, et al. Negative regulation of the NLRP3 inflammasome by A20 protects against arthritis. Nature 2014;512:69-73.

18. Liu K, Yao H, Wen Y, et al. Functional role of a long non-coding RNA LIFR-AS1/miR-29a/TNFAIP3 axis in colorectal cancer resistance to pohotodynamic therapy. Biochim Biophys Acta Mol Basis Dis 2018;1864:2871-80.

19. Litchfield LM, Appana SN, Datta S, et al. COUP-TFII inhibits NFkappaB activation in endocrine-resistant breast cancer cells. Mol Cell Endocrinol 2014;382:358-67.

20. Huang T, Yin L, Wu J, et al. MicroRNA-19b-3p regulates nasopharyngeal carcinoma radiosensitivity by targeting TNFAIP3/NF- $\kappa \mathrm{B}$ axis. J Exp Clin Cancer Res 2016;35:188.

21. Amjad N, Yang R, Li L, et al. Decrease of miR-19b$3 p$ in Brain Microvascular Endothelial Cells Attenuates Meningitic Escherichia coli-Induced Neuroinflammation via TNFAIP3-Mediated NF- $\mathrm{BB}$ Inhibition. Pathogens 2019;8:268.

22. Wang CM, Wang Y, Fan CG, et al. miR-29c targets TNFAIP3, inhibits cell proliferation and induces apoptosis in hepatitis B virus-related hepatocellular carcinoma. Biochem Biophys Res Commun 2011;411:586-92.

23. Xian J, Zeng Y, Chen S, et al. Discovery of a novel linc01125 isoform in serum exosomes as a promising biomarker for NSCLC diagnosis and survival assessment. 
Carcinogenesis 2021;42:831-41.

24. Sun X, Cai Y, Hu X, et al. Long noncoding RNA MAFGAS1 facilitates bladder cancer tumorigenesis via regulation of miR-143-3p/SERPINE1 axis. Transl Cancer Res 2020;9:7214-26.

25. Gong Y, Mao J, Wu D, et al. Circ-ZEB1.33 promotes the proliferation of human HCC by sponging miR-200a-3p and upregulating CDK6. Cancer Cell Int 2018;18:116.

26. Sarkar A, Rahaman A, Biswas I, et al. TGF $\beta$ mediated LINC00273 upregulation sponges mir200a-3p and promotes invasion and metastasis by activating ZEB1. J Cell Physiol 2020;235:7159-72.

27. Wang X, Ai L, Xu Q, et al. A20 Attenuates Liver Fibrosis

Cite this article as: Wan P, Chen Z, Huang M, Jiang $\mathrm{H}$, Wu H, Zhong K, Ding G, Wang B. miR-200a-3p facilitates bladder cancer cell proliferation by targeting the $A 20$ gene. Transl Androl Urol 2021;10(11):4262-4274. doi: 10.21037/tau-21-941 in NAFLD and Inhibits Inflammation Responses. Inflammation 2017;40:840-8.

28. Lopes CB, Magalhães LL, Teófilo CR, et al. Differential expression of hsa-miR-221, hsa-miR-21, hsa-miR-135b, and hsa-miR-29c suggests a field effect in oral cancer. BMC Cancer 2018;18:721.

29. Cavallari I, Grassi A, Del Bianco P, et al. Prognostic Stratification of Bladder Cancer Patients with a MicroRNA-based Approach. Cancers (Basel) 2020;12:3133.

(English Language Editor: J. Gray) 
A

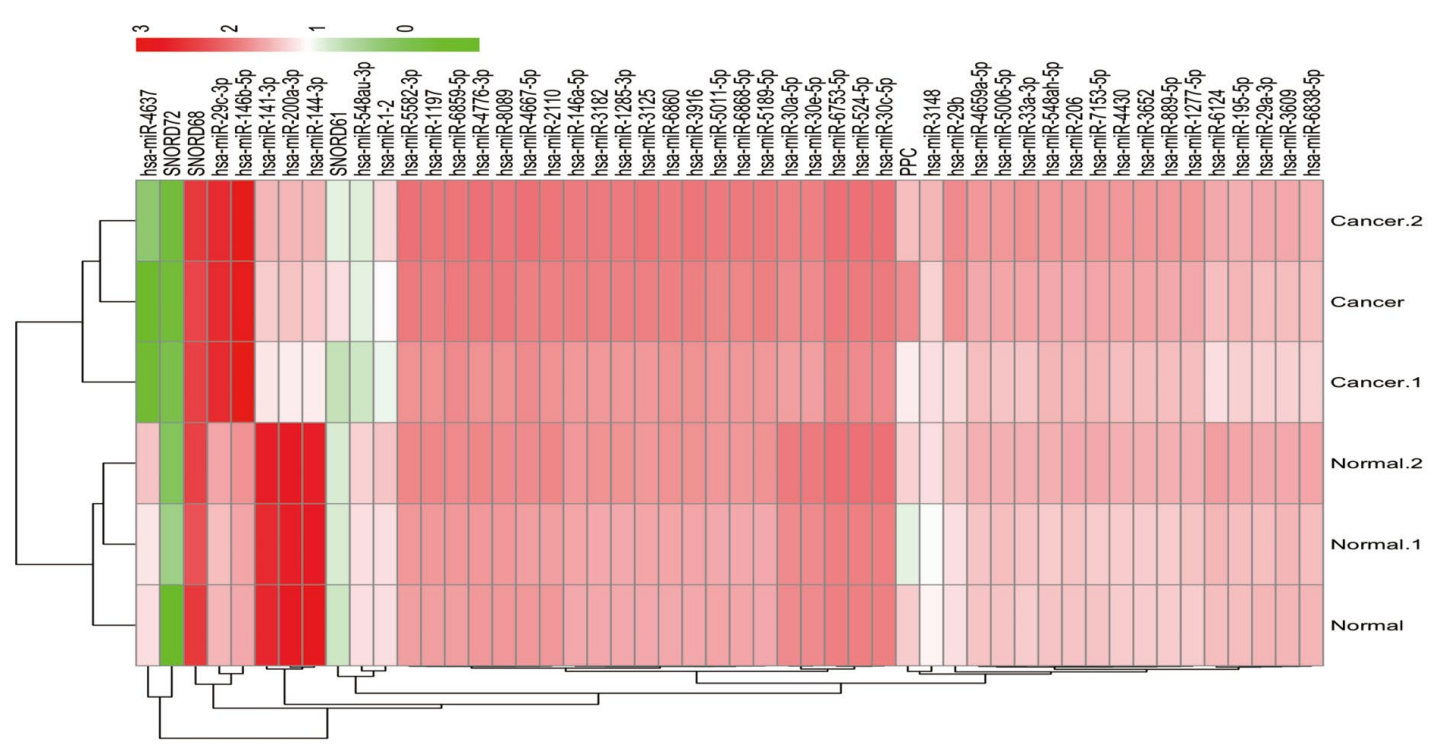

B

\begin{tabular}{|c|c|c|c|c|c|c|c|c|c|}
\hline \multirow[b]{2}{*}{ miRNA ID } & \multirow[b]{2}{*}{ Cancer Type } & \multirow[b]{2}{*}{ Design } & \multirow[b]{2}{*}{$\log \mathrm{FC}$} & \multirow[b]{2}{*}{ AveExpr } & \multirow[b]{2}{*}{ T value } & \multicolumn{3}{|c|}{ Status: } & UP : \\
\hline & & & & & & Pvalue & odj Pvalue & Status & Plot \\
\hline hso-mir-205-5p & blodder cancer & cancer vs normal & 494 & 9.58 & 14.84 & $1.43 c \cdot 9$ & $2.65 e-7$ & up & 司 \\
\hline hso-mif-200s-3p & blodder concer & concer vs normal & 5.77 & 8.96 & 13.16 & $6.26 \mathrm{e}-9$ & $7.72 \mathrm{e}-7$ & up & (1) \\
\hline hea-mirip.944 & bladder concer & concer vs normal & 5.62 & 5.82 & 12.49 & 1.19e.8 & $1.20 \mathrm{e}-6$ & UP & te \\
\hline hiso-mim-107 & blodder cancer & cancer vs normal & 2.67 & 14.76 & 10.74 & $7.27 e-8$ & $4,48 e-6$ & UP & 중 \\
\hline hsa-miR-1307-3p & bladder cancer & cancer vs normal & 3.32 & 7.68 & 10.22 & 1.300 .7 & $6.89 \mathrm{e}-6$ & UP & (6) \\
\hline hso-mif-24l-3p & bladder cancer & concer vs normal & 4.68 & 3.96 & 8.61 & $9.32 e \cdot 7$ & $3.700 .-5$ & up & c \\
\hline bsa-mili-135b-5p & biodder cancer & cancer vs normol & 5.42 & 1.19 & 8.36 & $1.31 \mathrm{e}-6$ & $5.02 e .5$ & UP & 5 \\
\hline hso-mip-4724-5p & blodder cancer & cancer vs normol & 5.36 & -0.48 & 8.02 & $2.066-6$ & $6.54 \mathrm{e}-5$ & UP & 둠 \\
\hline hso-mir-21-5p & blodder cancer & cancer vs normol & 3.67 & 13.40 & 792 & $2.39 e-6$ & $7.16 e-5$ & UP & 다 \\
\hline hsa-mif-191-5p & blodder concer & concer vs normal & 228 & 13.18 & 7.22 & $6.43 e-6$ & $1.49 e-4$ & UP & क \\
\hline hsa-mik.-6B87-3p & blodder concer & concer vs normol & 3.62 & .270 & 7.08 & $8.000-6$ & $1.75 e-4$ & UP & e \\
\hline hso-miR-210-3p & blodder cancer & cancer vs normal & 4.18 & 5.73 & 6.96 & $9.57 \mathrm{e}-6$ & $2.04 e-4$ & up & 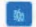 \\
\hline Hsa-mip-7641 & bladder cancer & concer vs normal & 3.56 & 6.16 & 6.90 & $1.04 \mathrm{e}-5$ & $2.17 e-4$ & UP & 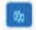 \\
\hline 1 spa-mit-301b-3p & biodder cancer & concer vs normal & 4.65 & -1.50 & 6.85 & $1.13 e \cdot-5$ & $2.24 \mathrm{e}-4$ & up & 间 \\
\hline hso-mir-2000-3p & bladder cancer & concer vs normal & 5.24 & 731 & 6.86 & $1.12 \mathrm{e} .5$ & $2.24 e-4$ & UP & 雨 \\
\hline
\end{tabular}

\section{BoxPlot}

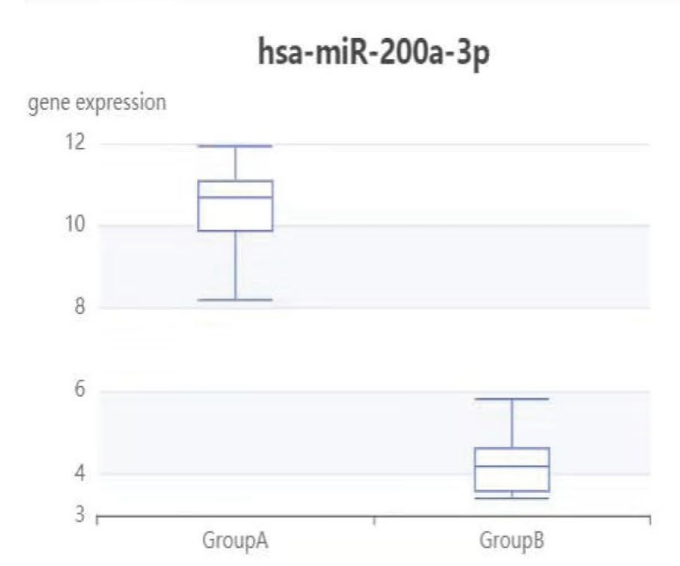

Group_A:

bladder cancer cancer

Group_B:

bladder cancer normal

Figure S1 The expression of miR-200a-3p between bladder cancer and normal tissues. (A) Heat map of Agilent miRNA microarray analysis data of bladder cancer tissues and adjacent nontumor tissues. (B) The expression of miR-200a-3p in cBiopPortal database. 


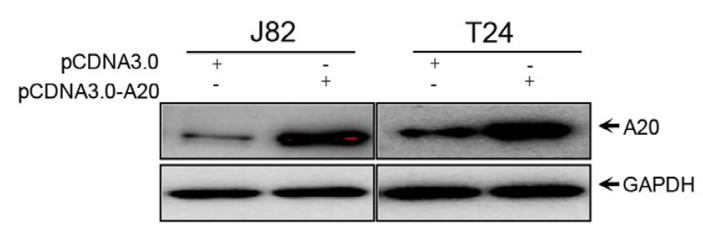

Figure S2 Transfection efficacy of A20 overexpression vector in J82 and T24 cells. Western blotting was performed to assess the transfection efficiency of pcDNA3.0-A20 in J82 and T24 cells. A20, TNF- $\alpha$-induced protein 3. 